\title{
Heart rate, ischaemic heart disease, and sudden cardiac death in middle-aged British men
}

\author{
A G Shaper, Goya Wannamethee, P W Macfarlane, Mary Walker
}

\begin{abstract}
Objective-To examine the relation between resting heart rate and new major ischaemic heart disease events in middle aged men with and without preexisting ischaemic heart disease.

Design-Prospective study of a cohort of men with eight years follow up for cardiovascular morbidity and mortality for all men.
\end{abstract}

Setting-General practices in 24 British towns (the British Regional Heart study). Subjects-7735 men aged 40-59 years drawn at random from the age-sex registers of one general practice in each town. Main outcome measures-Major ischaemic heart disease events such as sudden cardiac death, other deaths attributed to ischaemic heart disease, and non-fatal myocardial infarction.

Results-During the follow up period of eight years, 488 men had a major ischaemic heart disease event (217 fatal and 271 non-fatal). Of these, 117 were classified as sudden cardiac death (death within one hour of the start of symptoms) The relation between heart rate and risk of all major ischaemic heart disease events, ischaemic heart disease deaths, and sudden cardiac death was examined separately in men with and without pre-existing ischaemic heart disease. In men with no evidence of ischaemic heart disease, there was a strong positive association between resting heart rate and age adjusted rates of all major ischaemic heart disease events (fatal and non-fatal), ischaemic heart disease deaths, and sudden cardiac death. This association remained significant even after adjustment for age, systolic blood pressure, blood cholesterol, smoking, social class, heavy drinking, and physical activity, with particularly high risk in those with heart rate $\geqslant 90$ beats/min. The increased risk seen in those with increased heart rate was largely due to a significantly increased risk of sudden cardiac death, which was five times higher than in those with heart rate $<60$ beats $/ \mathrm{min}$. The effect of heart rate on sudden cardiac death was present irrespective of blood pressure or smoking state. In men with pre-existing ischaemic heart disease a positive association was seen between raised heart rate and risk of all major ischaemic heart disease events, ischaemic heart disease death, and sudden cardiac death, but the effect was less noticeable than in men without pre-existing ischaemic heart disease.

Conclusion-In this study of middle aged British men increased heart rate $\geqslant 90$ beats/min) is a risk factor for fatal ischaemic heart disease events but particularly for sudden cardiac death. The effect is not dependent on the presence of other established coronary risk factors and is most clearly seen in men free of pre-existing ischaemic heart disease at initial examination.

(Br Heart f 1993;70:49-55)

A high resting heart rate is associated with an increased risk of ischaemic heart disease ${ }^{1-8}$ and in some studies specifically with sudden cardiac death. ${ }^{1-2}$ It is well established that an increased resting heart rate is associated with hypertension ${ }^{9-11}$ and that heart rate is strongly influenced by smoking and physical activity, known risk factors for ischaemic heart disease. Whereas some studies have found heart rate to be an independent risk factor for ischaemic heart disease ${ }^{1-4}$ others have shown the association to be dependent on confounding risk factors. ${ }^{57}$ We examined the relation between resting heart rate measured on an electrocardiogram and risk of new major ischaemic heart disease events in middle aged British men, with a particular focus on mortality from ischaemic heart disease and on sudden cardiac death. The role of heart rate in influencing the risk of ischaemic heart disease is examined primarily in men without evidence of pre-existing ischaemic heart disease, with additional comment on those with pre-existing ischaemic heart disease.

Subjects and methods

The British Regional Heart Study is a prospective study of cardiovascular disease of 7735 men aged 40-59 selected from the age-sex registers of one group general practice in each of 24 towns in England, Wales, and Scotland. The criteria for selecting the town, the general practice, and the subjects as well as the methods of data collection have been reported. ${ }^{12}$ Research nurses gave each man a standard questionnaire that included questions on smoking habits, alcohol intake, and medical history. Several physical measurements were made, and blood samples (non-fasting) were taken for measurement of 
biochemical and haematological variables. Details of the measurement of serum lipid concentrations have been described. ${ }^{13}$ The men were classified according to their current smoking state-namely, those who had never smoked, ex-cigarette smokers, and current smokers. Those who had only ever smoked a pipe or cigars are grouped as never smoked. Ex-cigarette smokers who are currently pipe or cigar smokers are classified as ex-cigarette smokers. Alcohol consumption was recorded with questions on frequency, quantity, and type, similar to those used in the 1978 General Household Survey. Heavy drinkers were defined as those regularly drinking more than six drinks daily. The longest held occupation of each man was recorded and then coded in accordance with the Registrar General's occupational classification. Body mass index calculated as weight/height ${ }^{2}$ was used as an index of relative weight. Forced expiratory volume in one second $\left(\mathrm{FEV}_{1}\right)$ was measured with a Vitalograph spirometer (model J49-B2) with the subject seated. Two consecutive readings were made 15 seconds apart and the maximum of these two readings was used. The $\mathrm{FEV}_{1}$ values given in this paper are height standardised to $1.73 \mathrm{~m}$, the average height of the men in this study. The men were asked to indicate their usual pattern of physical activity, which included regular walking or cycling, recreational activity, and sporting activity. A physical activity score was derived for each man based on frequency and type of leisure activity. ${ }^{14}$ The men were grouped into six broad categories based on their total score: inactive, occasional, light, moderate, moderately/vigorous, and vigorous. Active men were those whose physical activity was moderate or greater.

\section{BREATHLESSNESS}

A modified version of the Medical Research Council questionnaire on respiratory symptoms (1966 version) was given at the initial examination. Each man was asked: (a) do you get short of breath walking with people your own age on level ground? (b) On walking up hills or stairs do you get more breathless than people your own age? (c) Do you ever have to stop walking because of breathlessness? Each affirmative answer scored 1 giving a possible score of 0 to 3 . Those who scored $\geqslant 2$ were defined as those reporting moderate to severe breathlessness.

\section{PRE-EXISTING DISEASE}

The men were asked to recall a doctor's diagnosis of angina, myocardial infarction, diabetes, and a number of other disorders listed on the questionnaire. The World Health Organisation (Rose) chest pain questionnaire was given to all men at the initial examination. ${ }^{15} \mathrm{~A}$ three orthogonal lead electrocardiogram was recorded at rest with the subject recumbent and having been at rest at least half an hour before the recording. The electrocardiogram preceded measurement of lung function and venepuncture for blood samples.

\section{ISCHAEMIC HEART DISEASE}

The men were separated into three groups according to the evidence of ischaemic heart disease present at screening. Group I had no evidence of ischaemic heart disease based on the World Health Organisation chest pain questionnaire or electrocardiogram and no recall of a doctor's diagnosis of ischaemic heart disease. Group II were men with evidence suggesting ischaemic heart disease short of a definite myocardial infarction. This group contained those with electrocardiographic evidence of possible or definite myocardial ischaemia or possible myocardial infarction, those with angina or a possible myocardial infarction according to the World Health Organisation chest pain questionnaire, or with recall of a doctor's diagnosis of angina. Group III were men with a previous definite myocardial infarction on electrocardiogram or who recalled a doctor's diagnosis of a myocardial infarction. In the analyses, men with pre-existing evidence of ischaemic heart disease consist of men in groups II and III.

\section{HEART RATE}

Heart rate was determined at screening from a three lead orthogonal electrocardiogram. All men were supine, and before the recording were resting while answering the questionnaire. On the basis of the eight second recording, the average $R R$ interval (seconds) during that period was calculated: heart rate $=60 /$ (average RR interval) beats. When a ventricular extrasystole was included in the eight second recording ( $n=209 ; 2 \cdot 7 \%)$, it was used in an estimate of heart rate/min. Some patients were in atrial fibrillation $(n=$ $49,0.06 \%)$; in such cases the occurrence of an extrasystole would have little or no effect on the heart rate calculation. Heart rate was not available in 52 men because of difficulties with electrocardiographic equipment. The men were classified into five groups based on heart rate: $<60=1429$ men $(18.6 \%), 60-69$ $=2475$ men $(32 \cdot 2 \%), 70-79=2101$ men $(27 \cdot 3 \%), 80-89=1034$ men $(13 \cdot 5 \%)$, and $\geqslant$ $90=644 \operatorname{men}(8 \cdot 4 \%)$.

\section{FOLLOW UP}

All men, whether or not they showed evidence of ischaemic heart disease at initial examination were followed up for all cause mortality and cardiovascular morbidity. Information on death was collected through the established "tagging" procedures provided by the NHS registers in Southport (for England and Wales) and Edinburgh (for Scotland). All cause mortality and major ischaemic heart disease events (fatal and nonfatal) are based on eight years of follow up for each man. A non-fatal myocardial infarction was diagnosed according to World Health Organisation criteria. Fatal events were defined as those with death from ischaemic heart disease (International Classification of Diseases (ICD) 9th revision codes 410-4) as the underlying cause. They comprised an ischaemic heart disease death in an individual 


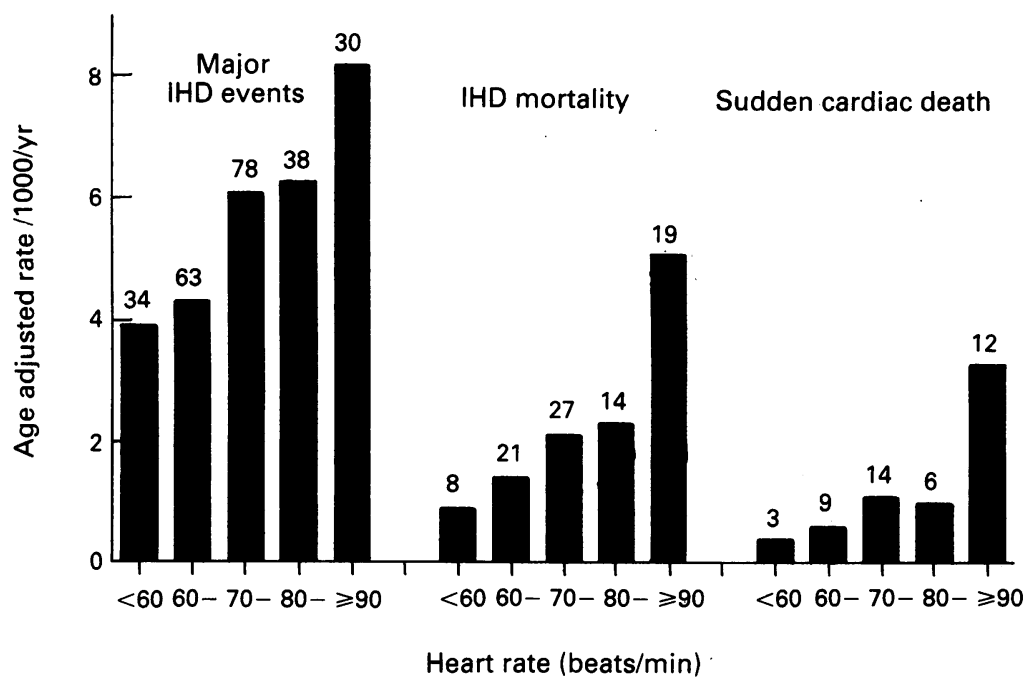

Figure 1 Age adjusted rates for major ischaemic heart disease (IHD) events, mortality from (IHD), and sudden cardiac death in men without pre-existing ischaemic heart disease in the five heart rate (beats $/ \mathrm{min}$ ) groups. $<60=1088 \mathrm{men}, 60-69=1870 \mathrm{men}$, $70-79=1619$ men, $80-89=747$ men, $\geqslant 90=445$ men. Absolute numbers of events are indicated. ease event. The mean resting heart rate at screening was 70.7 beats/min (SD $12 \cdot 8$ ) in 7683 men for whom heart rate was available. At initial examination, $25 \%$ of the men had evidence of ischaemic heart disease; $19.5 \%$ had ischaemic heart disease short of a definite myocardial infarction (group II), and 5.5\% had definite previous myocardial infarction (group III). The mean resting heart rate in these two groups (II and III) and group I (men free of pre-existing heart disease) were 71.7 beats $/ \mathrm{min}$ and 70.4 beats $/ \mathrm{min}$ respectively. The percentage of men with evidence of ischaemic heart disease was significantly higher in those with heart rate $\geqslant 80 /$ min than those with lower heart rate $(p<0.0001)$. The percentages of men with pre-existing ischaemic heart disease by the five heart rate groups were $24 \%, 24 \%, 23 \%, 28 \%$, and $31 \%$ (test for difference between the five groups; $\mathrm{p}$ $<0.0001)$. Because of the effect that the presence of ischaemic heart disease has on heart rate we have examined the relation between heart rate and risk of ischaemic heart disease separately in men with and without evidence of pre-existing ischaemic heart disease.

subject during the eight year follow up irrespective of a previous non-fatal event during that period. The certifying doctor was asked to complete an enquiry form that asked the duration from the start of symptoms to death-namely, < 1 hour, 1-24 hours or $>24$ hours. Sudden cardiac death was defined as an event in which death occurred within one hour of the start of symptoms. Only those for whom clear information was available regarding death within one hour were included as sudden cardiac death. Case fatality is defined as the proportion of the major ischaemic heart disease events in which death occurred during the first event during follow up and within 28 days of the start of symptoms, and in which the death certificate recorded ischaemic heart disease (ICD codes 410-4).

\section{STATISTICAL METHODS}

Multiple logistic regression was used to obtain the relative risk for the five heart rate groups adjusted for age, social class, smoking, heavy drinking, physical activity, systolic blood pressure, blood cholesterol, and blood glucose. Age, systolic blood pressure, blood cholesterol, and blood glucose were fitted as continuous variables, heart rate as four dummy variables (for the five groups), physical activity as five dummy variables (for the six physical activity groups), smoking as four dummy variables (never, ex, light, moderate and heavy), social class as two dummy variables (manual, non-manual, and armed forces) and heavy drinking as a 0 or 1 variable. Tests for trend were assessed by fitting heart rate as a continuous variable.

\section{Results}

During the follow up of eight years there were 488 major ischaemic heart disease events (217 fatal, 271 non-fatal) of which 117 were classified as sudden cardiac death. Data on heart rate were not available in 52 men of whom five had a major ischaemic heart dis-

\section{MEN WITHOUT PRE-EXISTING ISCHAEMIC}

HEART DISEASE

Figure 1 shows the age adjusted rate (1000/year) for all major ischaemic heart disease events (fatal and non-fatal), ischaemic heart disease mortality, and sudden cardiac death in men without pre-existing ischaemic heart disease by the five heart rate groups. There was a strong positive association with all these outcomes $(p<0.0001)$, with rates increasing progressively with increasing heart rate. Rates for mortality from ischaemic heart disease and in particular for sudden cardiac death, were considerably higher in those with heart rate $\geqslant 90$ beats/minute than in those with lower heart rates. Case fatality (first event that resulted in death within 28 days) increased significantly with increasing heart rate $(18 \%, 27 \%, 24 \%, 32 \%$, and $53 \%$ for the five heart rate groups respectively) - that is, those with raised heart rate were less likely to survive a major ischaemic heart disease event when it occurred.

\section{Heart rate and cardiovascular risk factors}

Several studies have shown strong associations between heart rate and cardiovascular risk factors that could influence the correlation between heart rate and major ischaemic heart disease events, notably blood pressure and smoking. The relations between heart rate and cardiovascular risk factors were examined for the five heart rate groups in men without pre-existing ischaemic heart disease (table available on request). Those with higher heart rate tended to be older ( $p<$ $0.01)$ and heavier $(p<0.01)$ and systolic and diastolic blood pressure, and blood cholesterol, blood glucose, and triglyceride concentrations increased significantly with increasing heart rate $(p<0.0001)$. There was little difference in mean high density lipoprotein cholesterol between the five heart rate groups. 
Table 1 Relative risk (95\% CI) of major ischaemic heart disease (IHD) events, mortality from IHD, and sudden cardiac death according to heart rate in men without pre-existing IHD

\begin{tabular}{|c|c|c|c|c|c|c|c|}
\hline \multirow{2}{*}{$\begin{array}{l}\text { Heart } \\
\text { rate }\end{array}$} & \multirow{2}{*}{$\begin{array}{l}\text { No of } \\
\text { men }\end{array}$} & \multicolumn{2}{|c|}{ Major IHD events $(n=243)$} & \multicolumn{2}{|c|}{ IHD mortality $(n=89)$} & \multicolumn{2}{|c|}{ Sudden cardiac death $(n=44)$} \\
\hline & & $(A)$ & (B) & (A) & (B) & $(A)$ & (B) \\
\hline $\begin{array}{l}<60 \\
60-69 \\
70-79 \\
80-89 \\
\geqslant 90 \\
\text { Test for trend }\end{array}$ & $\begin{array}{l}(1088) \\
(1870) \\
(1619) \\
(747) \\
(445)\end{array}$ & $\begin{array}{l}1.0 \\
1.1(0.7 \text { to } 1.6) \\
1.6(1.0 \text { to } 2.4) \\
1.6(1.0 \text { to } 2.6) \\
2.2(1.3 \text { to } 3.6) \\
p<0.01\end{array}$ & $\begin{array}{l}1.0 \\
1.0(0.6 \text { to } 1.5) \\
1.3(0.8 \text { to } 1.9) \\
1.1(0.7 \text { to } 1.8) \\
1.2(0.8 \text { to } 1.3) \\
\text { NS }\end{array}$ & $\begin{array}{l}1.0 \\
1.5(0.7 \text { to } 3.4) \\
2.3(1.1 \text { to } 5.2) \\
2.5(1.0 \text { to } 6.0) \\
5.5(2.3 \text { to } 12.9) \\
\text { p }<0.001\end{array}$ & $\begin{array}{l}1.0 \\
1.4(0.6 \text { to } 3.0) \\
1.8(0.8 \text { to } 4.0) \\
1.7(0.7 \text { to } 4.1) \\
3.3(1.4 \text { to } 7.8) \\
\mathrm{p}<0.01\end{array}$ & $\begin{array}{l}1.0 \\
1.7(0.5 \text { to } 6.4) \\
3.2(0.9 \text { to } 11.1) \\
2.8(0.7 \text { to } 11.4) \\
9.5(2.6 \text { to } 34.8) \\
p<0.001\end{array}$ & $\begin{array}{l}1.0 \\
1.6(0.4 \text { to } 5.8) \\
2.6(0.7 \text { to } 8.6) \\
1.9(0.5 \text { to } 7.4) \\
5.2(1.4 \text { to } 18.7) \\
p<0.01\end{array}$ \\
\hline
\end{tabular}

(A) adjusted for age; and (B) adjusted for age, social class, smoking, heavy drinking, physical activity, systolic blood pressure blood cholesterol and blood glucose.

The proportion of current smokers and heavy drinkers increased significantly with increasing heart rate. The proportion of active men decreased progressively with increasing heart rate. Social class was not significantly associated with heart rate although there was a tendency for the percentage of manual workers to increase with increasing heart rate. Although blood glucose was strongly associated with heart rate, a doctor's diagnosis of diabetes was not significantly associated with heart rate.

Heart rate and outcome of ischaemic heart disease Not all the factors associated with resting heart rate are independently predictive of new major ischaemic heart disease events. Therefore they need not be included in a multivariate analysis to find whether heart rate is independently associated with morbidity and mortality from ischaemic heart disease. Body mass index is not an independent predictor once blood cholesterol and blood pressures are taken into account. ${ }^{16}$ Triglyceride concentration is not an independent predictor of mortality from ischaemic heart disease once blood cholesterol is taken into account. ${ }^{17}$ Heavy drinking has been shown to be positively associated with sudden cardiac death. ${ }^{18}$ The relation between heart rate and morbidity and mortality from ischaemic heart disease has therefore been examined with adjustment for age, social class, smoking, heavy drinking, physical activity, systolic blood pressure, blood cholesterol, and blood glucose (table 1). Adjustment for all of these factors (column B) diminished the strong positive association seen with all major ischaemic heart disease events when only age was adjusted for (column $\mathrm{A}$ ), and the association was no longer significant. There was, however, still a significant positive association between heart rate and mortality from ischaemic heart disease and sudden cardiac death. In particular the risk of mortality from ischaemic heart disease was substantially increased at heart rates of 90 beats $/ \mathrm{min}$ and above, largely due to a noticeably increased risk of sudden cardiac death. Indeed, the proportion of sudden deaths from ischaemic heart disease was highest in those with high heart rate $(63 \%)$ and lowest in those with low ( $<60$ beats $/ \mathrm{min}$ ) heart rate $(38 \%)$.

Table 2 shows the relative risk of major ischaemic heart disease events, mortality from ischaemic heart disease, and sudden cardiac death in men with a raised heart rate $(\geqslant 90$ beats/min) compared with all other men adjusted for age, social class, smoking, heavy drinking, physical activity, systolic blood pressure, blood cholesterol, and blood glucose, separately for men with and without evidence of pre-existing ischaemic heart disease. In those without pre-existing ischaemic heart disease, after adjustment, increased heart rate was not associated with an increased risk of major ischaemic heart disease events but was significantly associated with an increased risk of mortality from ischaemic heart disease largely due to a significant increase in the risk of sudden cardiac death.

\section{Heart rate and hypertension}

Because of the strong association between heart rate and hypertension we have examined the relation between a high heart rate and mortality from ischaemic heart disease and sudden cardiac death in the presence or absence of hypertension in men with no preexisting ischaemic heart disease (fig 2). Hypertension was defined as men with measured systolic blood pressure $\geqslant 160 \mathrm{~mm} \mathrm{Hg}$ or diastolic blood pressure $\geqslant 90$ or on regular antihypertensive treatment. Eleven per cent of hypertensive men had a high heart rate compared with $6 \%$ in normotensive men. A raised heart rate was associated with over a twofold increase in relative risk (RR) of

Table 2 Relative risk (95\% CI) of major ischaemic heart disease (IHD) events, mortality from IHD and sudden cardiac death in men with raised heart rate ( $\geqslant 90$ beats/min) compared with all other men, in those with and without pre-existing $I H D$

\begin{tabular}{|c|c|c|c|c|c|c|}
\hline & \multicolumn{3}{|c|}{ Men with no evidence of IHD $(n=5769)$} & \multicolumn{3}{|c|}{ Men with evidence of pre-existing IHD $(n=1914)$} \\
\hline & $\begin{array}{l}\text { No of } \\
\text { Major IHD } \\
\text { events }\end{array}$ & $(A)$ & (B) & $\begin{array}{l}\text { No. of } \\
\text { Major IHD } \\
\text { events }\end{array}$ & (A) & (B) \\
\hline $\begin{array}{l}\text { IHD events } \\
\text { IHD mortality } \\
\text { Sudden death }\end{array}$ & $\begin{array}{r}243 \\
89 \\
44\end{array}$ & $\begin{array}{l}1.7(1.1 \text { to } 2 \cdot 5)^{\star \star} \\
3.2(1.9 \text { to } 5 \cdot 5)^{\star \star \star} \\
4.4(2.2 \text { to } 8 \cdot 7)^{\star \star \star}\end{array}$ & $\begin{array}{l}1.1(0.7 \text { to } 1.7) \mathrm{NS} \\
2.0(1.2 \text { to } 3.6)^{\star \star} \\
2.7(1.3 \text { to } 5.4)^{\star \star}\end{array}$ & $\begin{array}{r}240 \\
126 \\
71\end{array}$ & $\begin{array}{l}1.5(1.0 \text { to } 2.2)^{\star} \\
2.1(1.3 \text { to } 3.3)^{\star \star} \\
1.6(0.8 \text { to } 3.4) \mathrm{NS}\end{array}$ & $\begin{array}{l}1.4(0.9 \text { to } 2.1) \mathrm{NS} \\
2.0(1.2 \text { to } 4.9)^{\star} \\
1.5(0.8 \text { to } 3.0) \mathrm{NS}\end{array}$ \\
\hline
\end{tabular}

(A) adjusted for age; (B) adjusted for social class, smoking, heavy drinking, physical activity, systolic blood pressure, blood cholesterol, and blood glucose.

${ }^{\star} \mathrm{p}<0.05 ;{ }^{\star \star} \mathrm{p}<0.001 ;{ }^{\star \star \star} \mathrm{p}<0.0001$ 


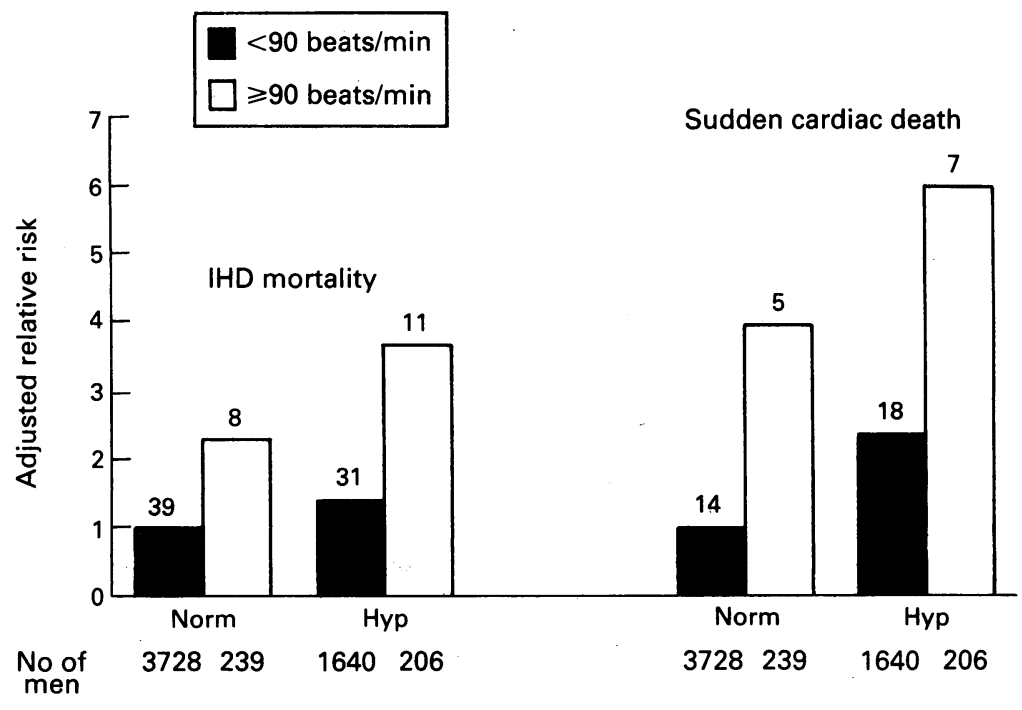

Figure 2 Relative risk of mortality from ischaemic heart disease (IHD) and sudden cardiac death by heart rate $(<90$ and $\geqslant 90$ beats/min) by presence or absence of hypertension in men without pre-existing ischaemic heart disease adjusted for age, social class, smoking, heavy drinking, physical activity, systolic blood pressure, blood cholesterol, and blood glucose. Absolute numbers of events are indicated. Norm, normotensive; hyp, hypertensive.
Table 3 Heart rate and measures of lung function

\begin{tabular}{lll}
\hline $\begin{array}{l}\text { Heart rate } \\
\text { (beats/min) }\end{array}$ & $\begin{array}{l}F E V_{1} \\
(\text { mean }(S E))\end{array}$ & $\begin{array}{l}\text { Breathlessness } \\
(\% \text { moderate to severe) }\end{array}$ \\
\hline$<60$ & $346 \cdot 9(2 \cdot 2)$ & $3 \cdot 4$ \\
$60-69$ & $343 \cdot 1(1 \cdot 7)$ & $3 \cdot 8$ \\
$70-79$ & $338 \cdot 5(1 \cdot 7)$ & $4 \cdot 4$ \\
$80-89$ & $329 \cdot 5(2 \cdot 8)$ & $6 \cdot 5$ \\
$\geqslant 90$ & $321 \cdot 3(4 \cdot 0)$ & $8 \cdot 1$ \\
\hline
\end{tabular}

resting heart rate might indicate a similarly impaired myocardial function, we have examined the relation between heart rate and lung function (breathlessness and $\mathrm{FEV}_{1}$ ) in men without evidence of pre-existing ischaemic heart disease (table 3).

There is a strong inverse association between resting heart rate and $\mathrm{FEV}_{1}(\mathrm{p}<$ $0.0001)$ and a strong positive association between resting heart rate and the proportion of men reporting moderate or severe breathlessness $(p<0.0001)$. Additional adjustment for $\mathrm{FEV}_{1}$ or breathlessness of the data in Table 2 made little difference to the strong positive association between resting heart rate and sudden cardiac death in men free from pre-existing ischaemic heart disease.

\section{Heart rate and antihypertensive treatment}

In the 5769 men with no pre-existing ischaemic heart disease, only 155 men were on antihypertensive treatment of whom eight had a raised heart rate. The men on treatment had a lower mean heart rate $(66 \cdot 7$ beats/min) than those not on antihypertensive treatment $(70.5$ beats $/ \mathrm{min})$. We have therefore examined the relation between raised heart rate and risk of sudden cardiac death excluding all the 155 men on antihypertensive treatment. The strong association between raised heart rate and sudden cardiac death remained $(R R=2.8,95 \%$ CI 1.4 to $5 \cdot 8$ ).

\section{Heart rate and smoking}

The relation between heart rate and ischaemic heart disease was also examined separately with reference to current smoking status in men without pre-existing ischaemic heart disease adjusting for age, social class, heavy drinking, physical activity, systolic blood pressure, blood cholesterol, and blood glucose. The higher risk of mortality and sudden death from ischaemic heart disease in those with raised heart rate was apparent in both non-smokers (never smokers and ex-cigarette smokers) and in current cigarette smokers. A high heart rate was associated with over a twofold increase in the risk of sudden cardiac death in both smokers and non-smokers.

\section{Heart rate and lung function}

We have previously reported on the role of decreased lung function and breathlessness as independent indicators of increased risk of a major ischaemic heart disease event in men free of pre-existing ischaemic heart disease.$^{19}$ It was suggested that this phenomenon might indicate early heart failure due to impaired myocardial function not detected by electrocardiography or the World Health Organization chest pain questionnaire. As an increased

\section{MEN WITH PRE-EXISTING ISCHAEMIC HEART DISEASE}

Figure 3 and table 4 show the age adjusted rates/1000/year for all major ischaemic heart disease events, mortality from ischaemic heart disease, and sudden cardiac death in men with evidence of ischaemic heart disease (groups II and III) according to resting heart rate. The risk of major ischaemic heart disease events, and in particular of mortality from ischaemic heart disease was increased in those with raised heart rate ( $\geqslant 90$ beats $/ \mathrm{min}$ ). Case fatality rate was also highest in those with a raised heart rate $(43 \%, 44 \%, 38 \%$, $36 \%$, and $50 \%$ for the five heart rate groups). Table 2 shows the age adjusted relative risk of men with a raised heart rate compared with those with a heart rate below 90 beats $/ \mathrm{min}$. disease events and mortality from ischaemic heart disease seen in those with raised heart rate was significant after adjusting for age (table 2; column A). Sudden cardiac death was also increased in those with raised heart rate although the difference was not significant or as noticeable as that seen in those with no evidence of ischaemic heart disease The increased risk of major ischaemic heart 


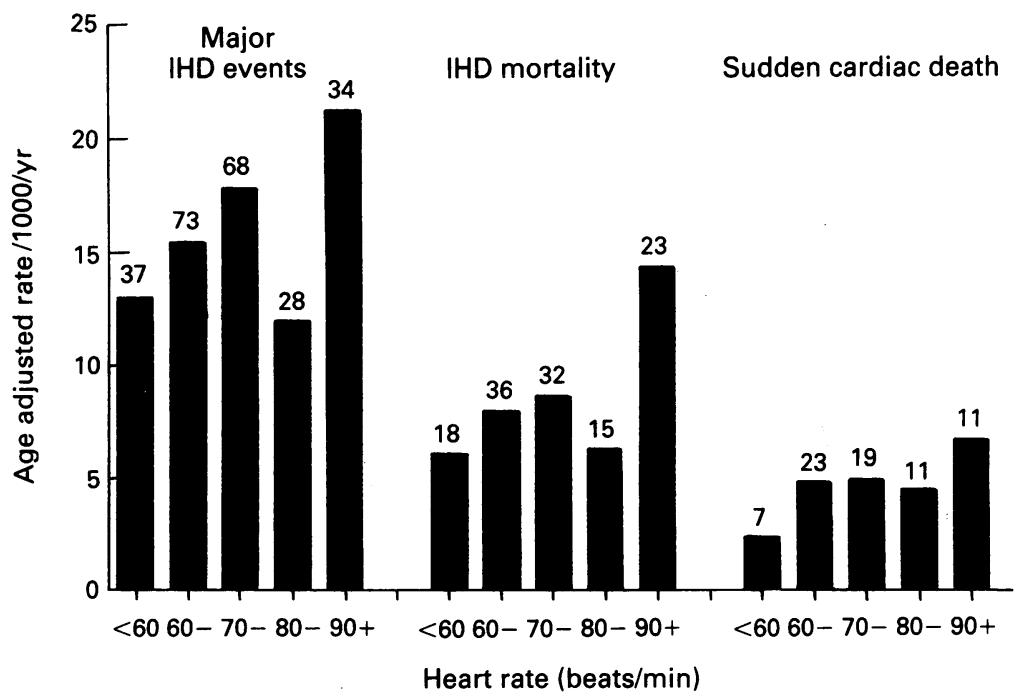

Figure 3 Age adjusted rates(1000/year) for major ischaemic heart disease (IHD) events, mortality from IHD, and sudden cardiac death in men with pre-existing ischaemic heart disease in the five heart rate (beats $/ \mathrm{min}$ ) groups: $<60 .=341 \mathrm{men}, 60-69=605 \mathrm{men}$, $70-79=482$ men, $80-89=287$, men, $\geqslant 90=199$ men. Absolute numbers of events are indicated.

Table 4 Age adjusted rate (1000/year) for major events, mortality from ischaemic heart disease (IHD) sudden death, and IHD case fatality (\%) in men with pre-existing IHD (groups II and III)

\begin{tabular}{llllll}
\hline \multicolumn{5}{c}{ Age adjusted rates/1000/year } \\
\cline { 3 - 6 } $\begin{array}{l}\text { Heart rate } \\
\text { (beats/min) }\end{array}$ & & $\begin{array}{l}\text { Major } \\
\text { IHD events }\end{array}$ & $\begin{array}{l}\text { IHD } \\
\text { mortality }\end{array}$ & $\begin{array}{l}\text { Sudden } \\
\text { death }\end{array}$ & $\begin{array}{l}\text { Case } \\
\text { fatality(\%) }\end{array}$ \\
\hline$<60$ & $(341)$ & $13 \cdot 0(37)$ & $6 \cdot 1(18)$ & $2 \cdot 4(7)$ & $43(16)$ \\
$60-69$ & $(605)$ & $15 \cdot 4(73)$ & $8 \cdot 0(36)$ & $4 \cdot 9(23)$ & $44(32)$ \\
$70-79$ & $(482)$ & $17.9(68)$ & $8 \cdot 6(32)$ & $5 \cdot 0(19)$ & $38(26)$ \\
$80-89$ & $(287)$ & $12 \cdot 0(28)$ & $6 \cdot 3(15)$ & $4 \cdot 6(11)$ & $36(10)$ \\
$\geqslant 90$ & $(199)$ & $21.3(34)$ & $14 \cdot 4(23)$ & $6 \cdot 8(11)$ & $50(17)$ \\
\hline
\end{tabular}

(table 2). Table 2 column $B$ also shows the $\mathrm{RR}$ of a raised heart rate ( $\geqslant 90$ beats $/ \mathrm{min}$ ) for ischaemic heart disease events, mortality, and sudden cardiac death adjusted for age, social class, smoking, heavy drinking, systolic blood pressure, blood cholesterol, and blood glucose. In those with pre-existing ischaemic heart disease, a raised heart rate was associated with a small but non-significant increase in risk of a major ischaemic heart disease event after these adjustments. Risk of mortality from ischaemic heart disease was significantly increased in those with an increased heart rate, similar to those without pre-existing ischaemic heart disease. The increase in risk of sudden cardiac death in those with raised heart rate was present but not as noticeable as that seen in those with no ischaemic heart disease. A test for interaction did not show a significant difference in the relation between raised heart rate and risk of sudden death in men with and without pre-existing ischaemic heart disease.

\section{Discussion}

In this study of middle aged men a raised heart rate ( $\geqslant 90$ beats $/ \mathrm{min}$ ) in men with no evidence of pre-existing ischaemic heart disease was strongly associated with an increased risk of major ischaemic heart disease events, mortality from ischaemic heart disease and sudden cardiac death. The increased death rate from ischaemic heart disease was largely due to a significant increase in the risk of sudden cardiac death. This positive association between resting heart rate and death from ischaemic heart disease, and sudden cardiac death in particular, has been reported in several prospective studies. ${ }^{1-8}$

\section{OTHER STUDIES}

It is well established that a raised heart rate is associated with hypertension and is strongly influenced by smoking, physical activity, and body weight, factors associated with risk of ischaemic heart disease. Some studies have found strong associations between heart rate and blood glucose and blood lipids, ${ }^{911}$ relations also seen in this study. In some studies, heart rate has been shown to be independently associated with ischaemic heart disease whereas others have shown the relation to be dependent on the presence of coronary risk factors. In the three Chicago studiesChicago People's Gas Company, the Chicago Heart Association, and the Western Electric Company-all of which excluded men with definite ischaemic heart disease, raised heart rate was associated with an increase in risk of mortality from cardiovascular and ischaemic heart disease and sudden cardiac death. After adjustment for age, blood pressure, smoking, blood cholesterol, and body weight, however, the relation with sudden cardiac death only remained significant in two of the three studies. ${ }^{1}$ A positive association was still present in the Western Electric Study but the trend was not significant. ${ }^{1}$ In the Kaiser Permanente Study a positive association was found with sudden cardiac death but this was largely accounted for by the presence of other coronary risk factors. ${ }^{7}$ In the Israeli study the strong positive association seen between heart rate and five year incidence of myocardial infarction was also diminished after adjustment for the established coronary risk factors. ${ }^{5}$ In the NHANES study a significant positive association was seen with mortality from coronary heart disease in black men even after adjustment for the risk factors, but an independent association was not seen in white men. ${ }^{4}$ In the Framingham study, however, raised heart rate remained significantly associated with mortality from cardiovascular ischaemic heart disease and sudden death even after adjustment for the established coronary risk factors. ${ }^{2}$

\section{THE BRITISH REGIONAL HEART STUDY}

Our findings are similar to those found in the Framingham study, which excluded men with overt evidence of ischaemic heart disease at screening. ${ }^{2}$ A strong positive association was seen between raised heart rate and ischaemic heart disease mortality and sudden death even after adjustment for age, social class, smoking, heavy drinking, physical activity, systolic blood pressure, blood cholesterol, and blood glucose. The increased risk of mortality from ischaemic heart disease was largely due to an increased risk of sudden cardiac death. The positive association with all major 
ischaemic heart disease events diminished after adjustment, indicating that resting heart rate is more associated with fatal than with non-fatal events. This was also found in the Framingham study, in which those with raised heart rate were less likely to survive a myocardial infarction and were at greater risk of having a sudden death. In the Chicago studies raised heart rate was shown to be independently associated with sudden death. It seems from this study and the Chicago and Framingham studies that raised heart rate is particularly associated with an increased risk of sudden cardiac death. This is likely to explain the lack of independent association seen in several studies where the overall incidence of myocardial infarction (fatal and non-fatal) was used after adjustment for coronary risk factors, as we have found in the British Regional Heart study. In the Gothenburg study, Tibblin et al showed no difference in heart rate between non-fatal cases and men free of disease, but they noted that fatal cases had the highest mean heart rate. ${ }^{20}$

\section{PRE-EXISTING ISCHAEMIC HEART DISEASE}

It is well established that heart rate is strongly associated with the presence of ischaemic heart disease, and an increased heart rate may be a reflection of underlying myocardial damage. Inclusion of men with evidence of ischaemic heart disease may thus obscure the role of heart rate in the risk of major ischaemic heart disease events. In our study increased heart rate was also associated with an increase in risk of mortality from ischaemic heart disease and sudden cardiac death in men with pre-existing ischaemic heart disease but the positive relation between heart rate and sudden cardiac death was less noticeable (table 2). The increased risk of fatal attacks may to some degree reflect the severity of the underlying myocardial damage.

\section{HEART RATE AND SUDDEN CARDIAC DEATH}

The mechanisms by which raised heart rate might predispose to sudden cardiac death are unclear. ${ }^{2}$ It has been suggested that the relation may be associated with lack of physical fitness, lipoprotein profile, and previous cardiovascular health. The strong association with sudden cardiac death found in this study, however, remained after excluding men with evidence of pre-existing ischaemic heart disease and taking account of physical activity and blood lipids. Heart rate is often associated with hypertension but in men with no ischaemic heart disease in this study, raised heart rate was associated with an increased risk in both normotensive and hypertensive subjects. Exclusion of the small number of men on antihypertensive treatment did not affect the outcome. The Framingham study suggests that "tachycardia may indicate subclinical loss of cardiac reserve as a result of impaired myocardial function leading to high fatality rate and increased propensity to sudden death." The independence of the correlation between heart rate and sudden cardiac death, and breathlessness and lung function in this study suggests that the underlying mechanism is not a diminished myocardial function with early cardiac decompensation. Neither breathlessness nor diminished $\mathrm{FEV}_{1}$ are adequate measures of left ventricular function, and this issue remains to be explored.

In this study of middle aged British men, raised heart rate ( $\geqslant 90$ beats $/ \mathrm{min}$ ) is a risk factor for fatal ischaemic heart disease events but particularly for sudden cardiac death. The effect is not dependent on the presence of other established coronary risk factors and is most clearly seen in men free of pre-existing ischaemic heart disease at initial examination.

The British Regional Heart study is a British Heart Department of Health and the Stroke Association.

1 Dyer AR, Persky V, Stamler J. Heart rate as a prognostic factor for coronary heart disease and mortality: findings in three Chicago epidemiologic studies. $A m \mathcal{F}$ Epidemio 1980;112:736-49.

2 Kannel WB, Kannel C, Paffenbarger RS, Cupples LA. Heart rate and cardiovascular mortality: the Framingham Study. Am Heart $₹$ 1987;113:1489-94.

3 Kannel WB, Wilson P, Blair SN. Epidemiological assessKannel WB, Wilson P, Blair SN. Epidemiological assess-
ment of the role of physical activity and fitness in develment of the role of physical activity and fitness in development of $109: 876-85$.

4 Gillum RF, Makue DM, Feldman JJ. Pulse rate, coronary heart disease and death: the NHANES 1 Epidemiologic Follow-up Study. Am Heart $\mathcal{F}$ 1991;121:172-7.

5 Medalie JH, Kahn HA, Neufeld HN, et al. Five-year myocardial infarction incidence II. Associations of single variables to age and birthplace. Fournal of Chronic Diseases 1973;26:329-49.

6 Schroll M, Hangerup LM. Risk factors of myocardial infarction and death in men aged 50 at entry. A ten-year prospective study from the Glostrup Population Studies. prospective study from the Glod Bull 1977;24:252-5.

7 Friedman GS, Klatsky AL, Siegelaub AB. Predictors of sudden cardiac death. Circulation 1975;51(suppl III): 164-9.

8 Paul O, Lepper MH, Phelan WH, et al. A longitudinal study of coronary heart disease. Circulation 1963;28: $20-31$.

9 Gillum RF. Epidemiology of resting heart rate in a national sample of men and women: associations with hypertension, coronary heart disease, blood pressure and other cardiovascular risk factors. Am Heart $\mathcal{F} 1988$; 116:163-74.

10 Green MS, Jucha E, Luz Yair. Inconsistencies in the correlates of blood pressure and heart rate. $\mathcal{f}$ Chron Dis 1986;79:261-70.

11 Williams PT, Haskell WL, Vranizan KM, et al. Association of resting heart rate with concentrations of lipoprotein subfractions in sedentary men. Circulation 1985; tein subfract

12 Shaper AG, Pocock SJ, Walker M, et al. British Regional Heart Study: cardiovascular risk factors in middle-aged men in 24 towns. BMF 1981;283:179-86.

13 Thelle DS, Shaper AG, Whitehead TP, Bullock DG, Ashby D, Patel I. Blood lipids in middle aged British men. Br Heart $\mathcal{F} 1883 ; 49: 205-13$.

14 Shaper AG, Wannamethee G. Physical activity and ischaemic heart disease in middle aged British men. $\mathrm{Br}$ Heart $\mathcal{f 1 9 9 1 ; 6 6 : 3 8 4 - 9 4 .}$.

15 Cook DG, Shaper AG, Macfarlane PW. Using the WHO (Rose) angina questionnaire in cardiovascular epidemiological studies. Int $\mathcal{f}$ Epidemiol 1989;18:607-13.

16 Shaper AG, Pocock SJ, Walker M, Phillips AN, Whitehead TP, Macfarlane PW. Risk factors for ischaemic heart disease: the prospective phase of the ischaemic heart disease: the prospective phase of the
British Regional Heart Study. $\mathcal{F}$ Epidemiol Community British Regional Heart
Health 1985;39:197-209.

17 Pocock SJ, Shaper AG, Phillips AN. Concentrations of high density lipoprotein cholesterol, triglycerides, and high density lipoprotein cholesterol, triglycerides, and
total cholesterol in ischaemic heart disease. $B M \mathcal{F} 1989$; 298:998-1002.

18 Wannamethee G, Shaper AG. Alcohol and sudden cardiac death. Br Heart $\mathcal{f}$ 1992;68:443-8.

19 Cook DG, Shaper AG. Breathlessness, lung function and the risk of heart attack. Eur Heart $f$ 1988;9:1215-22.

20 Tibblin G, Wilhelmsen L, Werko L. Risk factors for myocardial infarction and death due to ischaemic heart disease and other causes. Am $\mathcal{F}$ Cardiol 1975;35:514-22. 